\title{
Temporal discrimination as a function of marker duration
}

\author{
THOMAS H. RAMMSAYER \\ University of Jena, Jena, Germany \\ and \\ DETLEV LEUTNER \\ Erfurt University of Education, Erfurt, Germany
}

\begin{abstract}
In a series of three experiments, the effect of marker duration on temporal discrimination was evaluated with empty auditory intervals bounded by markers ranging from 3 to $300 \mathrm{msec}$ or presented as a gap within a continuous tone. As a measure of performance, difference thresholds in relation to a base duration of $50 \mathrm{msec}$ were computed. Performance on temporal discrimination was significantly better with markers ranging from 3 to $150 \mathrm{msec}$ than with markers ranging from 225 to $300 \mathrm{msec}$ or under the gap condition. However, within each range of marker duration (3-150 msec; 225-300 msec or gap) performance did not differ significantly. A fourth experiment provided evidence that the effect of marker duration cannot be explained in terms of marker-induced masking. A good approximation of the relationship between marker duration and temporal discrimination performance in the present experiments is a smooth step function, which can account for $99.3 \%$ of the variance of mean discrimination performance. Thus, the findings of the present study point to the conclusion that two different mechanisms are used in the processing of temporal information, depending on the duration of the auditory markers. The tradeoff point for the hypothetical shift from one timing mechanism to the other may be found at a marker duration of approximately $200 \mathrm{msec}$.
\end{abstract}

Because the auditory system has the finest temporal resolution of all the senses, auditory stimuli have been used in many studies on the processing of temporal information. Two types of stimuli can be applied in timing experiments: the filled interval, and the empty interval. In filled auditory intervals, a tone or noise burst is presented continuously throughout the interval, whereas in empty intervals, only the onset and the offset of the interval are marked. In empty intervals, no auditory stimulus is presented during the interval itself, and differences in stimulus characteristics of empty intervals are therefore limited to features of the markers used. The purpose of the following series of experiments was to investigate the effects of marker duration on the timing of brief empty auditory intervals.

With empty intervals, a conditio sine qua non for the perception of duration is that the onset and the offset markers be perceived as two distinct events: an interval has to appear to be between the two markers for the duration of the interval to be judged. In order to be perceived as two events, the markers must be separated by a minimal time interval, referred to as the auditory fusion

Data from Experiment 1 were presented at the Eighth Annual Meeting of the International Society for Psychophysics, Stockholm, July 1992. The authors would like to thank Carlen Pierce, Lester Krueger, and two anonymous reviewers for helpful comments. Correspondence concerning this manuscript should be addressed to $T$. H. Rammsayer, Institute of Psychology, University of Jena, Im Steiger 3/1, D-07743 Jena, Germany (e-mail: s5rath@rz.uni-jena.de). threshold. For auditory signals, critical thresholds of fusion as short as approximately $1 \mathrm{msec}$ have been reported (see, e.g., Fraisse, 1984; Green, 1971). Furthermore, within the framework of auditory fusion, Williams and Perrott (1972) showed that fusion threshold covaries positively with signal duration. At very brief signal durations of $3 \mathrm{msec}$, the fusion threshold for $1000-\mathrm{Hz}$ tones was $1.7 \mathrm{msec}$; for tones $300 \mathrm{msec}$ in duration, it was $8.8 \mathrm{msec}$. These results suggest that the temporal interval needed for one to hear two auditory signals as distinctly separate is a linear decreasing function of signal duration. Similarly, Penner (1975) found that for marker durations ranging from 1 to $10 \mathrm{msec}$, detection of an empty interval improved with decreasing marker duration; with marker durations ranging from 30 to $200 \mathrm{msec}$, however, detection of empty intervals was no longer affected.

Although the fusion threshold for brief auditory stimuli can be as low as $1 \mathrm{msec}$, the threshold for detecting a brief pause - that is, a gap - in a continuous noise requires a threshold value of approximately $10 \mathrm{msec}$ or more (Buunen \& van Valkenburg, 1979; Fraisse, 1984). A brief pause in a continuous tone, however, can be regarded as an empty interval with markers of very long duration. For studying thresholds for detection of a single gap in noise, subjects are presented with gaps embedded either in auditory signals lasting for 400 $500 \mathrm{msec}$ (see, e.g., Florentine \& Buus, 1984; Formby \& Muir, 1988) or in ongoing, continuous noise (e.g., Buunen \& van Valkenburg, 1979; Fitzgibbons, 1983, 1984). 
The threshold for detection of temporal gaps in noise has been shown to be a function of frequency, bandwidth, and amplitude (Fitzgibbons, 1983; Shailer \& Moore, 1983). In various studies, mean threshold values for gap detection with low-pass filtered noise and cutoff or center frequencies of $1000 \mathrm{~Hz}$ have varied from 6.9 to 12.5 msec (Fitzgibbons, 1983; Fitzgibbons \& GordonSalant, 1987; Formby \& Muir, 1988; Shailer \& Moore, 1983). Shailer and Moore (1985) estimated the $70.7 \%$ thresholds for gap detection by using a center frequency of $1000 \mathrm{~Hz}$ and five bandwidth values ranging from .0625 to 1.0 as a proportion of the center frequency. The resulting threshold values ranged from approximately $38 \mathrm{msec}$ for the narrowest bandwidth to $10 \mathrm{msec}$ for the largest bandwidth. Taken together, threshold values for gap detection are markedly higher than fusion threshold values. This means that for one to perceive discontinuity in a continuous tone, the gap must be longer in duration than the silent interval between two brief markers that enables one to perceive separation, which well agrees with Williams and Perrot's (1972) finding of a positive correlation between signal duration and fusion threshold.

If one assumes that Williams and Perrott's (1972) finding that auditory fusion threshold is a positive linear function of signal duration also applies to temporal discrimination of empty intervals, one should expect performance on temporal discrimination to be negatively correlated with marker duration. However, Fraisse (1963, 1984) put forward the idea of two distinct processes underlying auditory fusion and gap detection. Unlike the assumption of a negative linear relationship between marker duration and performance on temporal discrimination, the notion of two different perceptual mechanisms underlying temporal processing of empty intervals and gaps implies a nonlinear rather than a linear relationship. This is because a nonlinear step function appears to be a more appropriate reflection of the hypothetical transition from one perceptual process to the other. To date, however, there are no comprehensive data for the elucidation of the functional relationship between temporal discrimination and marker duration.

Surprisingly, there are very few published studies on the influence of marker duration on performance in time perception experiments. In an experiment with empty intervals ranging from 0.63 to $640 \mathrm{msec}$, Abel (1972) found that 10 -msec markers presented at $85 \mathrm{~dB}$ SPL resulted in better discrimination, as indicated by smaller threshold values, than did 300-msec markers presented at $70 \mathrm{~dB}$ SPL. Since marker duration and intensity may be integrated by the hearing mechanism, different levels in marker intensity were chosen in order to ensure identical energy levels (intensity $\times$ time) for both marker durations. However, in Abel's study, superior performance with short marker durations was more pronounced for empty intervals below approximately $160 \mathrm{msec}$ than it was for longer ones. This finding may suggest that some type of backward masking is effective with empty intervals below $160 \mathrm{msec}$, rather than two distinct perceptual processes as a function of marker duration. If the duration of the second marker influences temporal discrimination by partially masking the first marker, it is reasonable to assume that the effect of the second marker would be attenuated with increasing base durations of the empty interval and/or decreasing duration of the second marker.

In a study by Divenyi and Sachs (1978, Experiment 1), decreasing the amplitude of the first marker relative to that of the second marker caused substantial impairment in temporal discrimination performance. Since this impairing effect was much more pronounced for briefer than for longer base durations, it may reflect backward masking. In a subsequent study (Divenyi \& Sachs, 1978, Experiment 3), the duration of the first marker was fixed at $10 \mathrm{msec}$ while that of the second marker ranged from 10 to $300 \mathrm{msec}$, with all markers presented at $86 \mathrm{~dB} \mathrm{SPL}$. The unexpected outcome of this study was that, for empty intervals with base durations ranging from 10 to $90 \mathrm{msec}$, temporal discrimination thresholds essentially were an increasing function of base duration but were unaffected by marker duration, and thus they did not provide evidence for backward masking effects.

Similarly, a 37-dB increase in intensity of auditory 10msec markers of empty intervals with a base duration of $50 \mathrm{msec}$ resulted in the same small change in performance as was obtained for empty intervals with a base duration of $250 \mathrm{msec}$ (Carbotte \& Kristofferson, 1973). If an interaction between sensory effects of the two markers bounding the interval (i.e., masking) were being used as the basis for coding temporal information, it should be much less effective as a cue for temporal discrimination with a base duration of $250 \mathrm{msec}$ than with one of $50 \mathrm{msec}$. Therefore, it seems quite unlikely that some type of backward masking may account for the effect of varying marker duration (Carbotte \& Kristofferson, 1973).

In addition, for empty intervals with a base duration of $100 \mathrm{msec}$ and with marker durations ranging uniformly from 1 to $300 \mathrm{msec}$ in 1 -msec steps, Penner (1976) showed that randomizing the duration of the first marker produced a performance decrement nearly as large as randomizing the duration of both markers. On the other hand, randomizing the duration of the second marker also affected discrimination, but considerably less than did randomization of the first marker. This pattern of results may be indicative of a forward-masking effect produced by the first marker. For a more specific analysis of the effect of marker duration on temporal discrimination, a trial-by-trial breakdown of Penner's data would have been desirable. However, "technical difficulties allowed only the averages for each block to be collected in this study" (Penner, 1976, p. 469). To date, available data do not reveal to what extent masking may account for potential effects of marker duration.

Although there is some experimental evidence suggesting that temporal discrimination of empty intervals may be affected by marker duration, no systematic study on temporal discrimination as a function of marker du- 
ration appears to exist. Such data, however, are of particular interest with regard to the still open question of the relationship between marker duration and temporal discrimination. Elucidation of this relationship should lead to a better understanding of the mechanisms involved in the processing of temporal information. Therefore, the present study was designed to further investigate the effects of marker duration on temporal discrimination of empty auditory intervals.

In a first experiment, a nonlinear relationship between performance on temporal discrimination and marker duration was found. However, in Experiment 1 the temporal interval separating the two empty intervals to be compared varied as a function of marker duration. Therefore, Experiment 2 was designed to answer the question of whether the differences in performance on temporal discrimination observed in Experiment 1 could be considered a genuine function of marker duration. The outcome of Experiments 1 and 2 suggested that there is a critical marker duration somewhere between 30 and $300 \mathrm{msec}$. At this critical marker duration, a sudden shift toward higher threshold values points to a nonlinear function describing the relationship between performance on temporal discrimination and marker duration. Thus, the goal of Experiment 3 was to provide additional evidence for the existence of such a nonlinear functional relationship by investigating the effects of 75-, 150-, and 225-msec marker durations on temporal discrimination. The major focus of Experiment 4 was on whether the effects of marker duration observed in the preceding experiments could be explained in terms of marker-induced masking. A second goal of Experiment 4 was to check for possible confounding in the experimental method applied in Experiments 1, 2, and 3.

\section{EXPERIMENT 1}

In Experiment 1, performance on temporal discrimination was evaluated with empty auditory intervals bounded by 3-, 30-, or 300-msec markers on the one hand, or presented as a gap within a continuous tone on the other. Since Abel (1972) showed that duration discrimination of empty intervals briefer than $160 \mathrm{msec}$ was more susceptible to changes in marker duration than was discrimination of longer ones, in the present study $50-\mathrm{msec}$ intervals were used. If duration discrimination of empty intervals is a linear function of marker duration as has been suggested by fusion threshold studies, the expected outcome would be a decrease in performance with increasing marker durations.

\section{Method}

Subjects. The subjects were 12 male and 12 female undergraduate students ranging in age from 20 to 45 years (mean and standard deviation of age: $24.9 \pm 6.0$ years). The subjects were enrolled in an introductory psychology course at the University of Giessen. Their participation served as partial fulfillment of a course requirement. All subjects had normal hearing and were naive regarding the purpose of the experiment.
Apparatus and Stimuli. The presentation of the intervals and the recording of the subjects' responses were computer controlled. All auditory stimuli were $1000-\mathrm{Hz}$ square wave tones generated by a sound generator. Empty intervals were bounded by onset and offset markers 3,30 , and $300 \mathrm{msec}$ in duration. Within one trial, two empty intervals were presented with an interstimulus interval (ISI) of $900-(2 \times$ marker duration $) \mathrm{msec}$, resulting in ISIs of 894,840 , and $300 \mathrm{msec}$ for the $3-, 30-$, and $300-\mathrm{msec}$ marker durations, respectively. Thus, the ISIs represented the time between two pairs of markers bounding the first and second intervals. In the fourth experimental condition, the gap condition, a 3$\mathrm{sec}$ tone was used, with a first silent period (representing the first empty interval) occurring $1 \mathrm{sec}$ after tone onset. After this silent period, the tone was continued for $1 \mathrm{sec}$ before another silent period (representing the second empty interval) was started. After discontinuation for the second time, the tone was presented for another second. The stimuli were presented through headphones (Vivanco Model SR85). For each subject, the absolute thresholds for all four different kinds of stimuli were determined before the experiment, and an intensity level $48 \mathrm{~dB}$ above the individual's threshold was used in the experimental trials.

Procedure. An experimental session consisted of four blocks, with each block representing one experimental condition; the order of blocks was counterbalanced across subjects. Each block consisted of 50 trials, and each trial consisted of two empty intervals, one 50-msec standard interval, and one comparison interval. Durations of all empty intervals were measured from the offset of the first to the onset of the second marker.

The comparison interval varied in duration from trial to trial, depending on the subject's previous responses according to a transformed up-down procedure described by Levitt (1971) using a two-step rule, which converges on a probability of hits of $70.7 \%$. With the two-step rule, the difference between the standard and the comparison interval is incremented by one step size after each incorrect response and decremented by one step size after two successive correct responses. The initial value of the comparison interval was $75 \mathrm{msec}$.

The duration of the comparison interval changed with a constant step size of $8 \mathrm{msec}$ for Trials $1-10,4 \mathrm{msec}$ for Trials $11-30$, and $2 \mathrm{msec}$ for Trials 31-50. However, the lower limit of the comparison interval was set at $51 \mathrm{msec}$. Thus, the comparison interval always exceeded the 50 -msec standard interval. The order of presentation for the standard interval and the comparison interval was randomized and balanced, with each interval being presented first in $50 \%$ of the trials within each block.

The subjects were seated at a table with a computer keyboard and a monitor in a sound-attenuated room. To initiate a trial, the subject pressed the space bar. Then, after a delay of $900 \mathrm{msec}$, the two auditorily marked intervals were presented consecutively. The subject's task was to decide which of the two intervals was longer and to indicate his/her decision by pressing one of two designated keys.

As a measure of performance, mean differences between standard intervals and comparison intervals were computed for the last 20 trials within each block. This measure represents an estimate of the individual $70.7 \%$ difference threshold in milliseconds in relation to a standard interval of $50 \mathrm{msec}$. Thus, better performance on temporal discrimination is indicated by smaller threshold values.

Statistical analysis. A one-way analysis of variance (ANOVA) with the different experimental conditions as four levels of a repeated measurement factor was computed. Contrasts of statistically significant within-subjects effects were tested by Tukey's HSD test. For the within-subjects effects, the Greenhouse-Geisser correction for heterogeneity of variance was used to determine the appropriate significance level. 


\section{Results}

The ANOVA revealed that performance on temporal discrimination was significantly affected by stimulus characteristics $\left[F(3,69)=10.79, M S_{\mathrm{e}}=269.40, p<.001\right]$. With empty intervals bounded by either $3-\mathrm{msec}$ or 30 msec markers, performance on temporal discrimination was almost identical and did not differ significantly; the mean ( $\pm S E$ ) threshold value was $17.0 \pm 1.5 \mathrm{msec}$ for the 3 -msec markers and $18.0 \pm 1.8 \mathrm{msec}$ for the $30-\mathrm{msec}$ markers. However, empty intervals bounded by $300-\mathrm{msec}$ markers and the gap condition yielded much higher threshold values; the mean threshold value was $33.9 \pm 4.5 \mathrm{msec}$ for the $300-\mathrm{msec}$ markers and $38.6 \pm 4.9 \mathrm{msec}$ for the gap condition. Performance on temporal discrimination with empty intervals bounded by either $3-\mathrm{msec}$ or $30-\mathrm{msec}$ markers was significantly better than that with empty intervals bounded by 300 -msec markers ( $p<.01$ for both) and the gap condition $(p s<.001)$. There was no statistically significant difference in performance on temporal discrimination between empty intervals bounded by 300 msec markers and the gap condition. This lack of a difference in temporal discrimination between empty intervals bounded by $300-\mathrm{msec}$ markers and by $50-\mathrm{msec}$ gaps in a continuous tone suggests that temporal processing was equivalent for both types of stimuli. Also, there was no significant difference in temporal discrimination between empty intervals bounded by 3 - and 30 -msec markers; for both, temporal discrimination was found to be almost identical.

Although in Abel's (1972) study the effect of marker duration was less pronounced than in Experiment 1, her findings are in agreement with the outcome of the present experiment, indicating a significant increase in threshold values for marker durations of $300 \mathrm{msec}$ and above in comparison with marker durations ranging from 3 to $30 \mathrm{msec}$. The pronounced decrease in performance on temporal discrimination with either $300-\mathrm{msec}$ markers or under the gap condition in comparison with either 3- or 30-msec markers contradicts the assumption of a simple linear relationship between duration discrimination performance and marker duration. Instead of a simple linear model, the data seem to call for a more complex model. However, before any investigation of such a model could be undertaken, the effects observed in Experiment 1 needed to be replicated.

\section{EXPERIMENT 2}

In Experiment 1, changes in marker durations were confounded with changes in the ISIs; in fact, the temporal interval between the offset of the offset marker of the first empty interval and the onset of the onset marker of the second empty interval within a trial varied from $300 \mathrm{msec}$ for the $300-\mathrm{msec}$ marker condition to $894 \mathrm{msec}$ for the 3-msec marker condition, while the two gaps were separated by a temporal interval of $1 \mathrm{sec}$. Allan and Kristofferson (1974), who reviewed several duration discrimination studies, concluded that increasing ISIs from
500 to $2,000 \mathrm{msec}$ did not produce a decrement in discrimination performance. However, for ISIs of less than $500 \mathrm{msec}$, duration discrimination performance with empty intervals bounded by 10 -msec markers appeared to deteriorate relative to the fairly constant level for ISIs greater than $500 \mathrm{msec}$ (Carbotte, 1973). Therefore, the purpose of Experiment 2 was to answer the question of whether differences in duration discrimination performance found in Experiment 1 should be considered a function of changes in ISIs rather than marker duration. For this reason, the ISI-the time between the offset of the second marker for the first interval and the onset of the first marker for the second interval-was fixed at $900 \mathrm{msec}$ for all marker conditions. In the gap condition, the time between the two gaps was also held constant at $900 \mathrm{msec}$. If duration discrimination performance were independent of variations in ISIs, we would predict that an identical ISI for all four experimental conditions would result in the same pattern of results as observed in Experiment 1.

\section{Method}

Subjects. The subjects were 18 male and 6 female undergraduate students ranging in age from 20 to 37 years (mean and standard deviation of age: $28.6 \pm 4.0$ years). As in Experiment 1, the subjects were enrolled in an introductory psychology course at the University of Giessen. Their participation served in partial fulfillment of a course requirement. All of these subjects had normal hearing and had not participated in Experiment 1.

Apparatus. The apparatus was the same as in Experiment 1.

Design and Stimuli. The design was similar to that of Experiment 1 . As in Experiment 1, empty intervals were bounded by $1000-\mathrm{Hz}$ markers. However, within one trial the two empty intervals were presented with a constant ISI fixed at $900 \mathrm{msec}$ for all experimental conditions. Thus, presentation of the onset marker of the second empty interval started $900 \mathrm{msec}$ after termination of the offset marker of the first empty interval. In the gap condition, a 2.9-sec tone was used, with the first gap occurring $1 \mathrm{sec}$ after tone onset. After the first gap, the tone was continued for $900 \mathrm{msec}$ before the second gap was started. After the second gap, the tone was presented for another second. Order of conditions was counterbalanced across subjects.

Procedure. The procedure was identical to that of Experiment 1 .

\section{Results}

A one-way ANOVA with the different stimulus conditions as four levels of a repeated measurement factor revealed a statistically significant effect of marker duration $\left[F(3,69)=15.63, M S_{\mathrm{e}}=180.88, p<.001\right]$. As in Experiment 1, there was no difference in performance on temporal discrimination between empty intervals bounded by 3 - and 30 -msec markers; the mean threshold value was $17.8 \pm 1.6 \mathrm{msec}$ for the $3-\mathrm{msec}$ markers and $17.0 \pm 1.6 \mathrm{msec}$ for the $30-\mathrm{msec}$ markers. Empty intervals bounded by 300 -msec markers and the gap condition, however, resulted in markedly higher mean threshold values of $34.9 \pm 3.7$ and $37.3 \pm 3.6 \mathrm{msec}$, which did not differ significantly from each other. Threshold values obtained with 3 - and 30 -msec markers were significantly lower than those obtained with either 300 -msec markers or 
gaps $(p s<.001)$, indicating superior performance on temporal discrimination with either 3 - or $30-\mathrm{msec}$ markers as opposed to $300-\mathrm{msec}$ markers or gaps. The extremely close resemblance of the threshold values obtained in Experiment 2 to those obtained in Experiment 1 strongly suggests that the differences in performance on temporal discrimination observed in Experiments 1 and 2 were a function of marker duration rather than ISI.

\section{EXPERIMENT 3}

In Experiments 1 and 2, a very pronounced decrease in performance on temporal discrimination with 300 msec markers and under the gap condition as compared with either 3 - or $30-\mathrm{msec}$ markers was observed. This finding indicates that the difference threshold in relation to a standard interval of $50 \mathrm{msec}$ is not a single value. Instead, the difference threshold for temporal discrimination with empty intervals is a function of marker duration. Furthermore, the outcome of Experiments 1 and 2 that there were no significant differences in threshold values between the 3 - and $30-$ msec marker conditions on the one hand and between markers $300 \mathrm{msec}$ in duration or above on the other suggests that the threshold for temporal discrimination does not increase as a linear function of marker duration. This pattern of results points, rather, to a nonlinear function with a lower and upper asymptotic bound describing the relationship between marker duration and performance on temporal discrimination. However, a nonlinear function would imply the existence of a critical marker duration somewhere between 30 and $300 \mathrm{msec}$. At this critical marker duration a substantial performance decrement in temporal discrimination as indicated by a sudden shift toward higher threshold values should become evident. The goal of Experiment 3 , therefore, was to provide some additional experimental evidence for the notion of a nonlinear function describing the relationship between marker duration and temporal discrimination performance. For this purpose, the effects of three marker durations $(75,150$, and $225 \mathrm{msec}$ ) on temporal discrimination performance were investigated.

\section{Method}

Subjects. The subjects were 18 male and 6 female undergraduate students ranging in age from 22 to 38 years (mean and standard deviation of age: $28.9 \pm 4.0$ years). As in Experiments 1 and 2 , the subjects were enrolled in an introductory psychology course at the University of Giessen. Their participation served as partial fulfillment of a course requirement. All subjects had normal hearing, and none had participated in any of the other experiments.

Apparatus. The apparatus was the same as in Experiments 1 and 2.

Design and Stimuli. The design was identical to that of Experiment 2, except that in Experiment 3 the marker durations were 75,150 , and $225 \mathrm{msec}$. As in Experiment 2, the ISI-that is, the time between the pairs of markers bounding the first and the second interval---was fixed at $900 \mathrm{msec}$.
Procedure. The procedure was the same as in Experiments 1 and 2.

\section{Results}

An ANOVA confirmed that performance on temporal discrimination is significantly affected by changes in marker durations ranging from 75 to $225 \mathrm{msec}[F(2,46)=$ $\left.8.07, M S_{\mathrm{e}}=182.37, p<.01\right]$. With empty intervals bounded by 75 - and 150 -msec markers, the mean threshold values were $16.5 \pm 1.6$ and $20.7 \pm 2.6 \mathrm{msec}$, respectively. The two threshold values did not differ significantly. On the other hand, empty intervals bounded by 225 -msec markers yielded a much higher mean threshold value of $31.6 \pm 4.6 \mathrm{msec}$. Performance on temporal discrimination with empty intervals bounded by $225-\mathrm{msec}$ markers was significantly worse than that with empty intervals bounded by 75 - and 150-msec markers $(p<.001$ and $p<.05$, respectively).

In combination with the results from Experiments 1 and 2, the outcome of Experiment 3 indicated a nonlinear relationship between marker duration and temporal discrimination performance. The critical marker duration for a significant shift in discrimination performance appeared to be in the region of $200 \mathrm{msec}$, because increasing marker duration from 150 to $225 \mathrm{msec}$ resulted in a statistically significant increase in threshold values of more than $50 \%$, whereas increases in marker duration from 3 to $150 \mathrm{msec}$ on the one hand, and from $225 \mathrm{msec}$ to approximately $1 \mathrm{sec}$ (i.e., the gap condition) on the other, did not significantly affect performance on temporal discrimination $[t=.81, p=.42$, and $t=1.05, p=.30$, respectively].

However, when threshold values obtained with 3-and 30-msec markers (Experiments 1 and 2) are compared with those obtained with 75- and 150-msec markers (Experiment 3 ), it becomes obvious that, unlike the 3 - versus 30-msec comparison, the 75-versus $150-\mathrm{msec}$ comparison produced a trend, as was indicated by higher threshold values with increasing marker duration. Even though this trend was not significant, it went in the expected direction, and therefore, it appears to be necessary to justify the acceptance of the null hypothesis. Experimental designs that lack sensitivity may result in statistical comparisons that lack power and, correspondingly, cause an overacceptance of the null hypothesis (Lipsey, 1990). Therefore, it must be demonstrated that the null result obtained reflects a genuinely markerduration-independent process and is not the product of an inadequate experimental design or of an insensitive, noisy psychophysical procedure for threshold estimation.

The goal of Experiment 3 was to locate more specifically the position of the critical marker duration at which a sudden shift toward higher threshold values can be observed. The results of Experiments 1 and 2 suggested that the critical marker duration was located somewhere between 30 and $300 \mathrm{msec}$. Experiment 3 had to be designed so that the statistical power was sufficient for de- 
tecting at least the same effect size that had been observed in the previous two experiments. According to Cohen (1988), the observed effect sizes are calculated as the mean difference of paired observations from one sample (i.e., performance observed with $300-\mathrm{msec}$ minus performance observed with 30 -msec marker durations), divided by the standard deviation of the difference $\left[d(z)^{\prime}=m(z) / \operatorname{sigma}(z)\right.$; see Cohen, 1988, pp. 4850]. Thus, in Experiment $1, d(z)^{\prime}=(33.9-18.0) / 17.5=$ .9086 ; in Experiment $2, d(z)^{\prime}=(34.9-17.0) / 18.2=$ .9835. Consequently, for Experiment 3, the statistical power for detecting an effect size was chosen to correspond to the lower effect size $d(z)^{\prime}=.9086$ of Experiment 1. ${ }^{1}$ Cohen's (1988, p. 30) Table 2.3.2 indicates that the power is larger than .99. The "comparative detectable effect size" (CDES; see Cohen, 1988, p. 15), specified as that effect size detectable at $a(1)=.05$ with power $=.80$ for $n=24$ subjects, is $d=.86$ (see Cohen's Table 2.3.2), which corresponds to $d(z)^{\prime}=d / \operatorname{sqrt}(2)=.86 / 1.4142=$ .6081 .

On the basis of this analysis, Experiment 3 had a power of .80 for detecting an effect size of .6081 , which is still smaller than a conventional large effect size of .80 , but, nevertheless, larger than a conventional medium effect size of .50 (Cohen, 1988, p. 26). Thus, when one considers the nonsignificant contrast found in Experiment 3 for comparing the 75- and 150-msec marker durations, one can conclude that there was no "large" effect, which means that there was not a "large" decrement in performance when the marker duration increased from 75 to $150 \mathrm{msec}$. However, it cannot be ruled out that in the population of experimental subjects there may have been a true "medium" or even a true "small" decrement. On the other hand, from the two significant contrasts found in Experiment 3 for comparing both $75-$ and $150-\mathrm{msec}$ marker durations with the 225 -msec marker duration, one can conclude that there was a "large" decrement in performance when the marker duration increased from either 75 or 150 to $225 \mathrm{msec}$. This result is unlikely to be accounted for by the assumption of a single timing mechanism but rather calls for a model predicting a smooth transition between two different timing mechanisms underlying the processing of "short" and "long" marker durations.

\section{EXPERIMENT 4}

At this point, it still remains unclear whether the observed effects of marker duration were primarily due to the first or to the second marker, or to the combined effects of both markers. A substantial body of evidence indicates that both forward and backward masking may markedly impair duration discrimination of auditory intervals in the range of approximately $40-90 \mathrm{msec}$ (Allan \& Rousseau, 1977; Kallman, Beckstead, \& Cameron, 1988; Kallman, Hirtle, \& Davidson, 1986; Kallman \& Morris, 1984; Rammsayer \& Lima, 1991). Although the effect of masking on duration discrimination has been established by previous research, the available data do not unequivocally support the assumption that masking may also account for the effect of marker duration observed in Experiments 1, 2, and 3 of the present study (see the introduction).

If the second marker does influence temporal discrimination, one might have to postulate some type of backward masking. If so, it is reasonable to assume that the effect of the second marker would be attenuated with longer base durations. Divenyi and Sachs (1978, Experiment 1) showed that decreasing the amplitude of the first marker relative to that of the second marker resulted in progressive impairment in temporal discrimination performance. This performance decrement was much more pronounced for briefer than for longer base durations and thus may indicate backward masking. On the other hand, in their Experiment 3, Divenyi and Sachs (1978) investigated the effect of unequal marker durations on temporal discrimination of empty intervals bounded by $1000-\mathrm{Hz}, 86-\mathrm{dB}$ SPL markers. The duration of the first marker was fixed at $10 \mathrm{msec}$, whereas the second marker varied from 10 to $300 \mathrm{msec}$. In that study, performance on temporal discrimination with empty intervals ranging from 20 to $100 \mathrm{msec}$ was not affected by unequal marker durations. This finding suggests that even with offset markers of higher energy than that of the onset marker, backward masking is not very likely to occur within an empty interval as long as both markers are clearly detectable. Furthermore, the fact that changes in duration of the second marker ranging from 10 to $300 \mathrm{msec}$ did not affect temporal discrimination points to the interpretation that the duration of the first marker may be critical for the underlying timing mechanism.

In a study on the effects of marker variability on temporal discrimination, Penner (1976) compared threshold values for conditions in which the markers were fixed in duration and amplitude with conditions in which these parameters were randomly chosen. Observed decreases in performance on temporal discrimination with empty intervals ranging from 0.3 to $1,000 \mathrm{msec}$ appeared to be primarily due to variation of the first marker duration. Thus, the data reported by Divenyi and Sachs (1978) and Penner (1976) indicate that performance on temporal discrimination with empty intervals is more likely to be affected by the duration of the first rather than of the second marker. If this is the case, one might have to postulate some type of forward rather than backward masking.

One goal of Experiment 4, therefore, was to evaluate the effects of marker-induced forward and backward masking on temporal discrimination more directly. For this purpose, subjects were presented with one block of empty intervals bounded by $300-\mathrm{msec}$ onset and 3-msec offset markers and one block of empty intervals bounded by 3-msec onset and 300-msec offset markers, representing a forward-masking and a backward-masking condition, respectively. If temporal discrimination is more impaired by forward masking, this would indicate that temporal processing of brief empty intervals is mainly affected by the duration of the first marker. Otherwise, a more pronounced effect of backward masking would be 
indicative of the crucial role of the second marker for temporal processing of empty intervals.

In addition, in order to control for a possible confounding in the method applied in Experiments 1-3, it appeared to be advisable to also assess empty-interval durations longer than $50 \mathrm{msec}$. This was because it might have been that temporal discrimination was better for brief markers, ranging from 3 to $150 \mathrm{msec}$, than for markers longer than $225 \mathrm{msec}$, owing to the fact that the briefer markers were more similar in duration to the 50msec base duration of the empty intervals and thus provided a more salient reference or anchor stimulus. If this was true, a base duration of $300 \mathrm{msec}$ should result in better temporal discrimination with longer markers than with brief ones. To test this hypothesis, the subjects in Experiment 4 were also presented with two blocks of empty intervals with a base duration of $300 \mathrm{msec}$; in one block, intervals were bounded by 3 -msec markers, whereas in the other, intervals were bounded by $300-\mathrm{msec}$ markers.

\section{Method}

Subjects. The subjects were 11 male and 5 female undergraduate and graduate students of the University of Giessen ranging in age from 23 to 35 years (mean and standard deviation of age: $26.2 \pm 3.9$ years). Their participation served in partial fulfillment of course requirements. All subjects had normal hearing, and none participated in any of the other experiments.

Apparatus. The apparatus was the same as in Experiments 1, 2 , and 3 .

Design and Stimuli. An experimental session consisted of four blocks: two blocks of empty intervals with a base duration of $50 \mathrm{msec}$, and two blocks of empty intervals with a base duration of $300 \mathrm{msec}$. For the empty intervals with the 50 -msec base duration, one block consisted of intervals bounded by 300 -msec onset and 3-msec offset markers, representing the forward-masking condition; the other block consisted of intervals bounded by 3 msec onset and 300-msec offset markers, representing the backward-masking condition. For the empty intervals with the 300 -msec base duration, one block consisted of intervals bounded by 3 -msec markers, and one block consisted of intervals bounded by 300 -msec markers.

All markers were $1000-\mathrm{Hz}$ square wave tones presented at an intensity of $78 \mathrm{~dB}$. Within all trials the two empty intervals were presented with a constant ISI fixed at $900 \mathrm{msec}$ for all blocks. The order of blocks was counterbalanced across subjects.

Procedure. The procedure was similar to that of the three preceding experiments, with the exception that for the empty intervals with a base duration of $300 \mathrm{msec}$ the initial value of the comparison interval was $375 \mathrm{msec}$.

\section{Results}

A $t$ test revealed that temporal discrimination of empty intervals with a base duration of $50 \mathrm{msec}$ was not differently affected by either marker-induced forward or markerinduced backward masking $[t(15)=0.10, p=.92]$; the mean temporal discrimination threshold values were $66.3 \pm 7.7 \mathrm{msec}$ for empty intervals bounded by a 300 msec onset and a 3-msec offset marker, representing forward masking, and $65.4 \pm 6.2 \mathrm{msec}$ for empty intervals bounded by a 3 -msec onset and a 300 -msec offset marker, representing backward masking. Obviously, these thresh- old values were much higher than those found with empty intervals bounded by either 3 - or 300 -msec markers in Experiments 1 and 2 . The respective mean threshold values of Experiments 1 and 2 were $17.4 \mathrm{msec}$ for the 3 msec and $34.4 \mathrm{msec}$ for the $300-\mathrm{msec}$ marker conditions. Thus, increasing the duration of either the onset or the offset marker to $300 \mathrm{msec}$, while the duration of the other marker was held constant at $3 \mathrm{msec}$, hurt temporal processing much more than did increasing both marker durations from 3 to $300 \mathrm{msec}$. This pattern of results suggests that the difference in threshold values observed in Experiments 1 and 2 cannot be attributed solely to the influence of either the first or the second marker, since forward and backward masking caused almost identical decrements in performance.

Furthermore, when one compares the temporal discrimination of empty intervals with a base duration of $300 \mathrm{msec}$, it is clear that intervals bounded by $3-\mathrm{msec}$ markers were discriminated more accurately than the ones bounded by 300 -msec markers $[t(15)=3.07, p<.01]$. The resulting mean threshold values were $44.8 \pm 5.0 \mathrm{msec}$ and $84.6 \pm 12.4 \mathrm{msec}$ for the $3-$ and $300-\mathrm{msec}$ marker conditions, respectively. Clearly, this finding does not support the assumption of a possible confounding effect in the method applied in Experiments 1,2, and 3. Such a confounding effect might have been caused by the fact that briefer markers were more similar in duration to the 50 -msec base duration than were the longer markers and thus may have provided a useful reference or anchor stimuli. If this assumption had been valid, in the case of empty intervals with a base duration of $300 \mathrm{msec}$, better temporal discrimination should have been found with 300- than with 3-msec markers. The results obtained with empty intervals with a base duration of either $50 \mathrm{msec}$ (Experiments 1 and 2) or $300 \mathrm{msec}$ (Experiment 4) point, rather, to the conclusion that increasing marker duration from 3 to $300 \mathrm{msec}$ results in a marked performance decrement, irrespective of base duration.

\section{GENERAL DISCUSSION}

The results of the present series of experiments clearly demonstrate that empty intervals bounded by auditory markers ranging from 3 to $150 \mathrm{msec}$ are easier to discriminate than empty intervals bounded by markers ranging from 225 to $300 \mathrm{msec}$ as well as gaps in a continuous tone. The pattern of results is remarkably consistent across these experiments; the overall mean difference thresholds for 50 -msec empty intervals were $17.8 \mathrm{msec}$ for markers ranging from 3 to $150 \mathrm{msec}$ and $35.3 \mathrm{msec}$ for markers $225 \mathrm{msec}$ in duration or longer. It was demonstrated that when empty auditory intervals were bounded by markers ranging from 3 to $150 \mathrm{msec}$, subjects could reliably discriminate the durational difference between a 50-msec standard interval and a 67.8-msec comparison interval. In contrast, when the intervals were bounded by markers $225 \mathrm{msec}$ in duration or longer, the smallest difference that could be reliably detected was that between 
the 50-msec standard interval and an 85.3-msec comparison interval. Thus, difference thresholds for $50-\mathrm{msec}$ empty intervals bounded by markers $225 \mathrm{msec}$ in duration or longer were approximately two times greater than those for intervals bounded by markers ranging from 3 to $150 \mathrm{msec}$.

These differences in performance observed with shorter and longer markers point to two different timing mechanisms underlying temporal discrimination of empty intervals. On the one hand, if markers are short, a very sensitive mechanism seems to be effective. On the other hand, if markers are long, the mechanism seems to be less sensitive. The data of Experiments 1-3 point to a smooth transition between these two timing mechanisms. A good approximation of this kind of relationship between marker duration and temporal discrimination performance is a smooth step function with a lower as
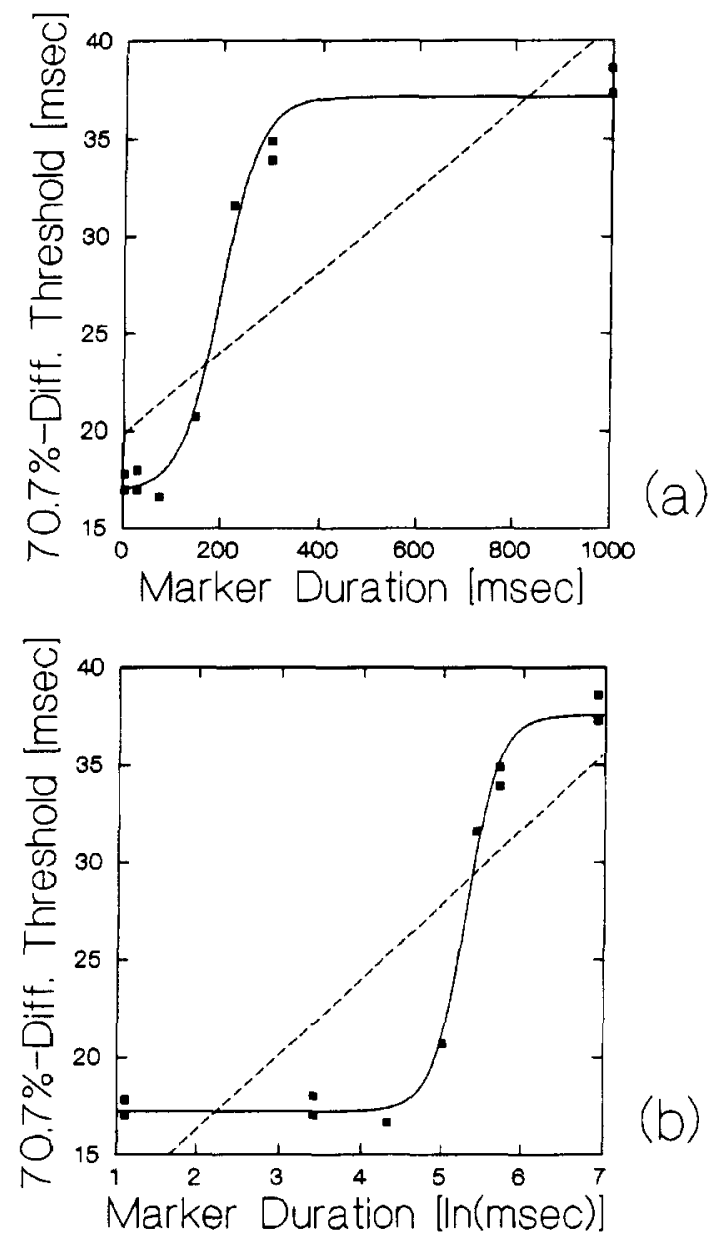

(b)

Figure 1. Relationship between marker duration and performance on temporal discrimination observed in Experiments 1-3. (a) Marker duration measured on the untransformed millisecond scale. (b) Marker duration measured on a logarithmic millisecond scale. Solid lines represent a logistic model for fitting a smooth step function to the data. Dashed lines represent a simple linear model for comparison. well as an upper asymptotic value and an almost linear middle portion. The family of logistic models (Birnbaum, 1968; Rasch, 1960) has precisely these features and therefore was chosen for fitting the mean threshold values obtained in Experiments 1-3 (see Figures 1a-1b). All in all, four parameters were neccessary: one parameter for estimating the position of the smooth step function on the marker duration scale (i.e., the point of inflection where acceleration ends and deceleration begins), two parameters for estimating the positions of the two asymptotic values on the performance scale, and one parameter for estimating the slope of the middle linear part of the function. Accordingly, the following model was specified:

$$
y=a+b \exp \frac{c[\ln (x)-d]}{1+\exp \{c[\ln (x)-d]\}} .
$$

In this model, $a$ represents the lower asymptotic performance, the sum $a+b$ represents the upper asymptotic performance, $c$ represents the slope, and $d$ represents the point of inflection that marks the position of the step function on the marker duration scale. Note that $y$ represents the mean performance on a linear scale, whereas $\ln (x)$ represents the marker duration $x$ on a logarithmic scale $[\ln (\mathrm{msec})]$. The parameters $a$ to $d$ of the logistic model were estimated by means of the nonlinearregression-program module of SYSTAT (Wilkinson, 1990). The estimate for the lower asymptotic value is $a=17.195$, the estimate for the upper asymptotic value is $a+b=17.195+20.376=37.571$, the estimate for the slope is $c=4.905$, and the estimate for the position of the step function on the marker duration scale [measured in $\ln (\mathrm{msec}$ )] is $d=5.291$ (which corresponds to approximately $198 \mathrm{msec}$ ). This model accounts for $99.269 \%$ of the variance of the performance variable and is shown in Figure $1 b$.

In addition, a conventional and simple linear model,

$$
y=a+c \ln (x),
$$

with intercept $a$ and slope $c$, was fitted to provide a comparison. The resulting estimates are $a=8.569$ and $c=$ 3.863. This simple model accounts for only $70.701 \%$ of the variance of the performance variable and is also pictured in Figures $1 \mathrm{a}$ and $1 \mathrm{~b}$. The difference in amount of variance accounted for by the two models is significant $[F(2,6)=122.6, p<.001]$. Therefore, it can be concluded that the more complex model of a logistic smooth step function fits the relationship between marker duration and discrimination performance much better than the simple model of a linear function. Note that this also holds when marker duration is not measured on the logarithmic $\ln (\mathrm{msec})$ scale, but on the untransformed millisecond scale. In the latter case (see Figure 1a), the logistic model with parameters $a=16.913, b=20.231$, $c=0.025$, and $d=200.000$ accounts for $98.740 \%$ of the variance of discrimination performance, whereas the simple linear model with parameters $a=19.827$ and $c=$ 0.021 accounts for $69.671 \%$ of the variance, the differ- 
ence again being highly significant $[F(2,6)=66.9, p<$ $.001]$.

Comparison of Figures $\mathrm{la}$ and $\mathrm{lb}$ indicates that, with marker duration measured on the $\ln (\mathrm{msec})$ scale instead of the untransformed millisecond scale, the points representing experimental conditions are more uniformly spread over the marker duration scale. The points representing brief marker durations are extremely clustered in Figure $1 \mathrm{a}$ but are more discernible in Figure $1 \mathrm{~b}$, the smooth step function is clearer. Furthermore, from Figure $1 \mathrm{~b}$ it can be seen that there indeed is a lower asymptote that is excellently fitted by the logistic function.

Before accepting the assumption of two distinct timing mechanisms as a function of marker duration, we have to provide some evidence that the results obtained in the present study were in fact produced by marker duration and were not due to factors such as marker intensity or masking. There should have been no appreciable effect of marker intensity on temporal discrimination in the present study, since all markers were presented at an intensity level of $48 \mathrm{~dB}$ above each subject's individual sensation threshold; all markers had the same loudness. In addition, as has been shown in several studies, changes in marker intensity do not produce changes in temporal discrimination as long as the markers are clearly detectable (Carbotte \& Kristofferson, 1973; Divenyi \& Danner, 1977; for a review, see Allan \& Kristofferson, 1974).

When the empty interval to be discriminated is very short, changes in temporal discrimination may be due to forward- or backward-masking effects, with one marker partially masking the other. In their experiments on temporal discrimination of filled auditory intervals, Kallman and his colleagues (Kallman et al., 1988; Kallman et al., 1986) have found that forward masking and backward masking exert equivalent effects on temporal discrimination. These authors concluded that auditory duration masking is the result of central rather than peripheral processing. They attributed their results to a "central timekeeper" (Kallman et al., 1988, p .35) and hypothesized that both forward and backward masking may cause a misassignment of neural pulses generated by an internal pacemaker. Although Kallman and his colleagues did not study empty intervals, the finding of Experiment 4 demonstrating that temporal discrimination of empty intervals with a base duration of $50 \mathrm{msec}$ is markedly affected by increases in the duration of either the onset or the offset marker from 3 to $300 \mathrm{msec}$ suggests that the misassignment hypothesis also holds for the effects of marker duration. At first sight, the data obtained in Experiment 4 support Kallman's finding that forward- and backward-masking effects on temporal discrimination are of the same magnitude. Since forward as well as backward masking caused an almost identical performance decrement, there is no evidence that the duration of either the first or the second marker bounding an empty interval may be more critical for temporal discrimination.

Within the framework of Kallman's misassignment hypothesis, effects of marker duration would be attrib- uted solely to marker-induced masking. However, there is considerable room for doubt that masking in fact occurred in Experiments 1-3, because, in general, for auditory masking effects to occur, the mask must be longer or more intense than the target (e.g., Deatherage \& Evans, 1969; Massaro, 1972; Massaro, Cohen, \& Idson, 1976). These basic requirements, however, were not met by the markers used in Experiments 1-3, because within each experimental condition, onset and offset markers were identical with regard to intensity and duration parameters. Furthermore, masking effects on temporal discrimination were shown to decrease as the interval between the target and the mask increased. Both forward and backward masking effects tend to level off with intervals longer than approximately $200 \mathrm{msec}$ (Kallman et al., 1988; Kallman et al., 1986). For this reason, the effect of marker duration observed in Experiment 4 with 300 msec empty intervals cannot be explained in terms of forward or backward masking.

As another possibility that could explain effects of marker duration, the stimulus context has to be taken into consideration. Penner (1976) found that randomizing the intensity or duration of noise bursts bounding empty intervals resulted in a marked increase in threshold values as compared with those for fixed marker control conditions. Randomizing marker duration or marker intensity within a block of trials can be considered as an increase in task uncertainty, because subjects do not know the exact stimulus that will be presented in any given trial. However, when marker intensity was changed from block to block but held constant within each block, no such pronounced changes in discrimination performance could be observed (Carbotte \& Kristofferson, 1973). Such a deleterious effect of stimulus uncertainty may point to higher level, nonsensory effects that can interact with temporal information processing (Woods, Sorkin, \& Boggs, 1979). However, since in the present study durations of the onset and offset markers were held constant within each experimental condition, the performance decrement found for marker durations above approximately $200 \mathrm{msec}$ cannot be explained in terms of a randomization effect but must be considered a genuine function of marker duration per se.

At this point, it seems rather unlikely that masking or a randomization effect can account for the observed effect of marker duration. Nevertheless, the nature of the two hypothetical timing mechanisms underlying temporal discrimination of empty intervals still remains unclear. Ison, O'Connor, Bowen, and Bocirnea (1991) showed in rats that the capability for detecting gaps in white noise is lost after functional cortical depression. This loss was restricted to gap detection while processing of pulses or offsets remained unaffected, and the authors concluded that the processing of auditory gaps depends primarily on cortical mechanisms. On the other hand, Rammsayer and Lima (1991) demonstrated that temporal discrimination of empty intervals bounded by 3 -msec markers was not affected by increasing cognitive load in a dual-task procedure. Furthermore, in an experiment on effects of prac- 
tice with empty intervals, also marked by 3 -msec clicks, Rammsayer (1994b) found no effect of practice over 20 testing sessions, pointing to the existence of a very basic biological timing mechanism that, unlike many cortical functions, is not susceptible to experience and training. These findings support the notion that empty intervals bounded by relatively brief markers are processed almost automatically at a lower level of the central nervous system and beyond cognitive control (Rammsayer, 1994a, 1994b; Rammsayer \& Lima, 1991).

When one compares fusion threshold values and thresholds for gap detection, it is obvious that threshold values for gap detection are much higher than fusion threshold values (see the introduction). Therefore, it is tempting at first sight to assume that temporal discrimination of empty intervals bounded by markers below approximately $200 \mathrm{msec}$ and auditory fusion share a common underlying timing mechanism on the one hand, and that temporal discrimination of empty intervals bounded by markers above $200 \mathrm{msec}$ and detection of temporal gaps in continuous noise share a common underlying timing mechanism on the other. However, it is important to note that in Williams and Perrott's (1972) study, fusion thresholds appear to have been a linear function of stimulus duration, whereas the results of the present study on temporal discrimination point to the existence of a nonlinear function relating marker duration to temporal resolution. These divergent findings suggest the assumption that the perceptual mechanism underlying temporal fusion is different from the mechanism underlying temporal discrimination. This conclusion is consistent with evidence suggesting that fusion depends primarily on characteristics of auditory processing and not on processing of duration per se (Florentine \& Buus, 1984), whereas temporal discriminations, although not completely independent of nontemporal characteristics of the marker, are "generally unaffected by large variations in the intensive, frequency, and bandwidth characteristics of the marker" (Allan, 1979, p. 351).

Finally, our data may shed some light on the question of how to define the duration of an empty interval. Whereas some researchers measure intervals from marker onset to marker onset (e.g., Divenyi \& Danner, 1977; Divenyi \& Sachs, 1978), others, as we did in the present study, define the durations of the intervals to be discriminated as those between the offset of the first and the onset of the second marker (e.g., Abel, 1972; Carbotte \& Kristofferson, 1973; Grondin, 1993; Penner, 1976; Rammsayer, 1994b). The outcome of the present study, demonstrating that auditory markers ranging from 3 to $150 \mathrm{msec}$ do not affect the temporal discrimination of empty intervals, clearly supports the latter assumption. If internal timing of empty intervals were started at the onset of the first marker and terminated by the onset of the second marker, given a base duration of $50 \mathrm{msec}$, an increase in marker duration from 3 to $150 \mathrm{msec}$ should result in higher threshold values.
To summarize, the outcome of the present study suggests that there is a qualitative difference in the way empty auditory intervals are processed, depending on the duration of the onset and offset markers bounding the interval. Furthermore, the results of the present study indicate that a shift takes place in the perceptual mechanism underlying temporal processing of empty intervals at a marker duration of approximately $200 \mathrm{msec}$. Whether this effect of marker duration also holds true for empty intervals with base durations other than $50 \mathrm{msec}$ would need to be established in further investigations. However, there is some preliminary evidence from Experiment 4 suggesting that increasing the marker duration from 3 to $300 \mathrm{msec}$ also adversely affects temporal discrimination of empty intervals with a base duration of $300 \mathrm{msec}$.

\section{REFERENCES}

ABEL, S. M. (1972). Discrimination of temporal gaps. Journal of the Acoustical Society of America, 52, 519-524.

Allan, L. G. (1979). The perception of time. Perception \& Psychophysics, 26, 340-354.

Allan, L. G., \& Kristofferson, A. B. (1974). Psychophysical theories of duration discrimination. Perception \& Psychophysics, 16, 26-34.

Allan, L. G., \& Rousseau, R. (1977). Backward masking in judgments of duration. Perception \& Psychophysics, 21, 482-486.

Birnbaum, A. (1968). Some latent trait models and their use in inferring an examinee's ability. In F. M. Lord \& M. R. Novick (Eds.), Statistical theories of mental test scores (pp. 395-479). Reading, MA: Addison-Wesley.

Buunen, T. J. F., \& van Valkenburg, D. A. (1979). Auditory detection of a single gap in noise. Journal of the Acoustical Society of America, 65, 534-537.

CARbotte, R. M. (1973). Retention of time information in forcedchoice duration discrimination. Perception \& Psychophysics, 14, 440-444.

Carbotte, R. M., \& Kristofferson, A. B. (1973). On energydependent cues in duration discrimination. Perception \& Psychophysics, 14, 501-505.

COHEN, J. (1988). Statistical power analysis for the behavioral sciences (2nd ed.). Hillsdale, NJ: Erlbaum.

Deatherage, B. H., \& Evans, T. R. (1969). Binaural masking: Backward, forward, and simultaneous effects. Journal of the Acoustical Society of America, 46, 362-371.

DivenYI, P. L., \& DANNER, W. F. (1977). Discrimination of time intervals marked by brief acoustic pulses of various intensities and spectra. Perception \& Psychophysics, 21, 125-142.

Divenyi, P. L., \& SaChs, R. M. (1978). Discrimination of time intervals bounded by tone bursts. Perception \& Psychophysics, 24, 429-436.

FitzgibBons, P. J. (1983). Temporal gap detection in noise as a function of frequency, bandwidth, and level. Journal of the Acoustical Society of America, 74, 67-72.

FitzgibBons, P. J. (1984). Tracking a temporal gap in band-limited noise: Frequency and level effects. Perception \& Psychophysics, 35, 446-450.

Fitzgibbons, P. J., \& Gordon-Salant, S. (1987). Temporal gap resolution in listeners with high-frequency sensorineural hearing loss. Journal of the Acoustical Society of America, 81, 133-137.

FLorentine, M., \& BuUs, S. (1984). Temporal gap detection in sensorineural and simulated hearing impairments. Journal of Speech \& Hearing Research, 27, 449-455.

Formby, C., \& MuIR, K. (1988). Modulation and gap detection for broadband and filtered noise signals. Journal of the Acoustical Society of America, 84, 545-550.

Fraisse, P. (1963). The psychology of time. New York: Harper \& Row. 
FraISSE, P. (1984). Perception and estimation of time. Annual Review of Psychology, 35, 1-36.

Green, D. M. (1971). Temporal auditory acuity. Psychological Review, 78, 540-551.

Grondin, S. (1993). Duration discrimination of empty and filled intervals marked by auditory and visual signals. Perception \& Psychophysics, 54, 383-394.

Ison, J. R., O'Connor, K., Bowen, G. P., \& Bocirnea, A. (1991). Temporal resolution of gaps in noise by the rat is lost with functional decortication. Behavioral Neuroscience, 105, 33-40.

Kallman, H. J., Beckstead, J. W., \& Cameron, P. A. (1988). Ipsilateral and contralateral masking of duration. Perception \& Psychophysics, 43, 31-37.

Kallman, H. J., Hirtle, S. C., \& Davidson, D. (1986). Recognition masking of auditory duration. Perception \& Psychophysics, 40, 4552.

Kallman, H. J., \& Morris, M. D. (1984). Duration perception and auditory masking. In J. Gibbon \& L. G. Allan (Eds.), Timing and time perception (Annals of the New York Academy of Sciences, Vol. 423, pp. 608-609). New York: New York Academy of Sciences.

LEviTT, H. (1971). Transformed up-down methods in psychoacoustics. Journal of the Acoustical Society of America, 49, 467-477.

LIPSEY, M. W. (1990). Design sensitivity: Statistical power for experimental research. Newbury Park, CA: Sage.

Massaro, D. W. (1972). Perceptual images, processing time, and perceptual units in auditory perception. Psychological Review, 79, 124-145.

Massaro, D. W., Cohen, M. M., \& Idson, W. L. (1976). Recognition masking of auditory lateralization and pitch judgments. Journal of the Acoustical Society of America, 59, 434-441.

Penner, M. J. (1975). Persistence and integration: Two consequences of a sliding integrator. Perception \& Psychophysics, 18, 114-120.

PenNer, M. J. (1976). The effect of marker variability on the discrimination of temporal intervals. Perception \& Psychophysics, 19, 466-469.
RAMMSAYER, T. H. (1994a). A cognitive-neuroscience approach for elucidation of mechanisms underlying temporal information processing. International Journal of Neuroscience, 77, 61-76.

RAMMSAYER, T. H. (1994b). Effects of practice and signal energy on duration discrimination of brief auditory intervals. Perception \& Psychophysics, 55, 454-464.

RAMmSAYER, T. H., \& Lima, S. D. (1991). Duration discrimination of filled and empty auditory intervals: Cognitive and perceptual factors. Perception \& Psychophysics, 50, 565-574.

RASCH, G. (1960). Probabilistic models for some intelligence and attainment tests. Copenhagen: Nielsen \& Lydicke.

Shailer, M. J., \& Moore, B. C. J. (1983). Gap detection as a function of frequency, bandwidth, and level. Journal of the Acoustical Society of America, 74, 467-473.

Shailer, M. J., \& Moore, B. C. J. (1985). Detection of temporal gaps in bandlimited noise: Effects of variations in bandwidth and signalto-masker ratio. Journal of the Acoustical Society of America, 77, 635-639.

WILKINSON, L. (1990). SYSTAT: The system for statistics. Evanston, IL: SYSTAT Inc.

Williams, K. N., \& PerrotT, D. R. (1972). Temporal resolution of tonal pulses. Journal of the Acoustical Society of America, 51, 644647.

Woods, D. D., Sorkin, R. D., \& Boggs, G. J. (1979). Stimulus context and duration discrimination. Perception \& Psychophysics, 26, 127. 132.

\section{NOTE}

1. The statistical power for detecting this effect size can be looked up in Cohen's $\left(1988\right.$, p. 30) power tables for $a(1)=.05, d=d(z)^{\prime}$. $\operatorname{sqrt}(2)=.9086 \cdot 1.4142=1.2849, n=24$.

(Manuscript received January 17, 1995; revision accepted for publication February 15, 1996.) 